\title{
Uma Casa Comum, um projeto comum: político, social e ambiental
}

\section{A Common House, a common project: Political, social and environmental}

\author{
Benedita Izabel Rosa*
}

Recebido: 27/08/2017. Aprovado: 29/11/2017.

Resumo: Em 2016, o tema escolhido para a Campanha da Fraternidade Ecumênica (CFE) foi: "Casa Comum, nossa responsabilidade". Esta campanha foi organizada pelo Conselho Nacional de Igrejas Cristãs do Brasil (CONIC), e teve por objetivo geral refletir sobre a questão do saneamento básico. Tais reflexões estão contidas no seu Texto-Base e demonstram que esse é um direito fundamental para todas as pessoas e, como todos os outros direitos, requer o nosso empenho, à luz da fé, a lutar por políticas públicas e atitudes responsáveis que garantam a integridade e o futuro de nossa Casa Comum. O livro do Profeta Amós, que inspirou o lema desta campanha, "Quero ver o direito brotar como fonte e correr a justiça qual riacho que não seca" $(A m 5,24)$, é uma revelação de que também naquela época já havia crises sociais agudas, fundamentadas por um progresso econômico que não se traduzia em igualdade e justiça para todos. Nessa linha de reflexão, incluir-se-á também o pensamento do Papa Francisco contido em sua Carta Encíclica Laudato Si', cujo conteúdo contempla o mesmo raciocínio do Texto-Base da CFE-2016. Para evitar que assunto tão relevante seja esquecido, propõe-se, como objetivo do presente artigo, a retomada constante da leitura dos documentos aqui referenciados, cujas reflexões possam contribuir para despertar em nós uma consciência que se concretize em atitudes responsáveis para a preservação da nossa Casa Comum.

Palavras-chave: Casa Comum. Responsabilidade. Justiça.

Abstract: In 2016, the theme chosen for the Campaign of Ecumenical Fraternity (CFE) was: "Common Home, our responsibility." Organized by the National Council of Christian Churches of Brazil (CONIC), CFE has the overall objective of ensuring the right to sanitation for all people and commit ourselves in the light of faith, public politics and responsible attitudes to ensure the integrity and the future of our common home. The book of the prophet Amos, who inspired the

* Mestranda em Teologia pelo Programa de Pós-Graduados em Teologia da Pontifícia Universidade Católica de São Paulo, Campus Ipiranga.

E-mail: bizabelrosa@ig.com.br 
motto of this campaign, "I want to see the right sprout as the source and run the justice which stream that does not dry out" (Am 5:24), is a revelation that also at that time had already acute social crises based on economic progress did not translate into equality and justice for all. In this line of thought, also include the thought of Pope Francis contained in his Encyclical Letter Laudato Si', therefore, its content covers the same reasoning Text-Base CFE-2016. To prevent such a relevant subject is forgotten, it is proposed, the objective of this article, the constant resumption of the reading of the documents referenced herein, whose reflections can contribute to awaken in us a consciousness that materializes in responsible attitudes towards the preservation of our Common Home.

Keywords: Common Home. Responsibility. Justice.

\section{Introdução}

Impressionante constatar que, em muitos lugares, desde o âmbito privado, nas ruas, em bares, além de escolas e setores públicos políticos das esferas municipais, estaduais e federais, a grande maioria das pessoas não fala e nem forma opiniões acerca da questão do saneamento básico, que é antes de tudo, direito de todos os cidadãos e cidadãs. Portanto, é mais que um direito, é uma questão de justiça.

Diante disso, talvez seja possível afirmar que a questão do saneamento básico em nosso país é uma das áreas, cuja real dimensão e importância para a vida de todos, a maioria das pessoas infelizmente pouco conhece. Essa falta de conhecimento deve-se, em primeiro lugar, à ineficiência dos serviços públicos municipais prestados à população, em descumprimento à legislação vigente. Em segundo lugar, à falta de esclarecimentos, ou seja, ao ocultamento à população local de dados estatísticos reais por parte das prefeituras, sobre a quantas andam os serviços de saneamento, que incorporam não só questões de ordem sanitária, mas também de justiça social e ambiental.

Dessa forma, é notória a escassez dos debates sobre o saneamento básico. Por outro lado, é bastante salutar verificar iniciativas como a da Campanha da Fraternidade 2016, organizada pelo Conselho Nacional de Igrejas Cristãs (CONIC) ${ }^{1}$ e reforçada por alguns especialistas. Tal iniciativa, além de esclarecer à população que o saneamento básico no Brasil se encontra permeado de desigualdades, comparando às regiões mais ricas em relação às mais pobres, trouxe também à tona que a questão

1 Igreja Católica Apostólica Romana (ICAR), Igreja Evangélica de Confissão Luterana no Brasil (IECLB), Igreja Episcopal Anglicana do Brasil (IEAB), Igreja Presbiteriana Unida do Brasil (IPUB), Igreja Sirian Ortodoxa de Antioquia (ISOA). 
do saneamento básico é um problema que se arrasta há muito tempo, conforme o levantamento de dados constantes no Texto-Base da Campanha. Acerca disso, propõe-se aqui elucidar alguns pontos considerados relevantes para esse estudo.

Baseado especialmente no Texto-Base da Campanha da Fraternidade Ecumênica de 2016 e complementado com o pensamento do Papa Francisco, em sua Carta Encíclica Laudato Si', este estudo busca dar continuidade às reflexões a respeito do difícil contexto em que vivemos, com relação às políticas sociais do nosso país, em especial as focadas no saneamento básico, e, mais além, com as questões de descuido para com a "Casa Comum".

Parece-nos fundamental, esclarecer que o conceito de saneamento passa a ser tratado em termos de saneamento, saneamento básico e saneamento ambiental. Considerando que o nosso estudo foca no termo do saneamento básico como justiça, cidadania e responsabilidade social, relacionamos abaixo sua especificidade, de acordo com o Texto-Base:

O saneamento básico significa o conjunto de serviços, infraestruturas e instalações fisicas, educacionais, legais e institucionais que garantam: a) Abastecimento de água potável, desde a captação até as ligações prediais e respectivos instrumentos de medição; b) Esgotamento sanitário: coleta, transporte, tratamento e disposição final adequados dos esgotos sanitários, desde as ligações prediais até o seu lançamento final no meio ambiente; c) Limpeza urbana e manejo de resíduos sólidos: coleta, transporte, transbordo, tratamento e destino final do lixo doméstico, hospitalar, industrial e do lixo originário da varrição e limpeza de ruas; d) Drenagem e manejo das águas pluviais urbanas: transporte, detenção ou retenção para evitar enchentes. Também inclui o tratamento e disposição final das águas pluviais drenadas nas áreas urbanas. (Lei n. 11.445/07 - art. 3); e) Articulação entre o saneamento básico e as políticas de desenvolvimento urbano e regional de habitação, de combate à pobreza e de sua erradicação, de proteção ambiental, de promoção da saúde e outras de relevante interesse social voltadas para a melhoria da qualidade de vida, para as quais o saneamento básico seja fator determinante (Lei $n .11 .445 / 07$, art. $2, \S 6^{\circ}$ ). ${ }^{2}$

Contudo, pode-se perceber a complexidade que envolve a questão do saneamento básico e também a sua relevância, pois, acima de tudo a sua implantação torna-se essencial à vida humana e à proteção do meio

2 TEXTO-BASE. Campanha da Fraternidade Ecumênica 2016, n. 33, p. 16. 
ambiente. Logo, não se trata apenas de ação que busca construir a justiça e garantir o direito social do cidadão, especialmente para os pequenos e mais pobres, mas é, principalmente, dever do Estado, cuja finalidade deverá ser a de proporcionar uma real melhora na qualidade de vida de todas as pessoas, em especial para aquelas que notoriamente apresentam-se com profundas desigualdades de classe, raça/etnia, gênero etc. ${ }^{3}$

Sobre esse contexto, como já foi dito anteriormente, o Texto-Base da CFE 2016 sustenta e auxilia a reflexão, pois, o seu conteúdo está ordenado nas três principais partes metodológicas: ver, julgar e agir. $\mathrm{O}$ momento primeiro é "ver", ou seja, informar sobre a realidade humana, observar todos os seus sinais nos campos mais relevantes: econômico, político, social, ideológico e religioso. O segundo momento é "julgar", formar novos paradigmas com o sentido de iluminar, de criticar, de confrontar a realidade à luz da ótica cristã, na fidelidade a Deus, aos irmãos e à vida. Trata-se de analisar as causas e as consequências dos fatos, de questionar criticamente o que se vê para buscar um novo estilo de vida. Por último, o "agir" é o momento de caminhar para uma ação verdadeiramente transformadora da realidade constatada e criticada. É uma nova atitude diante da vida; uma transformação pessoal e integral que atinge todos os níveis da pessoa e tem consequências diretas e indiretas na sociedade 4 .

Curiosamente, na mesma época em que se elaborava a redação do Texto-Base, o Papa Francisco redigia a sua Carta Encíclica Laudato $S i$ ', publicada no dia 24 de maio de 2015. Apesar dos dois documentos serem pensados paralelamente, há entre eles uma relevante coincidência sobre o cuidado com a "Casa Comum"; são documentos que não podem ser classificados como um tratado de uma 'Ecologia Verde', pois vão muito além.

Constata-se, portanto, que ambos os textos têm preocupação única e ao mesmo tempo abrangente, considerando o valor próprio de cada criatura e o sentido humano da ecologia. Os referidos documentos tocam na necessidade de debates sinceros e honestos e a responsabilidade dos governos para com os cidadãos e cidadãs. Fazem referência à ética do

3 Cf. PONTIFÍCIO CONSELHO JUSTIÇA E PAZ. Compêndio da Doutrina Social da Igreja. Trad. CNBB, São Paulo: Paulinas, 2011, n. 412.

4 BRIGHENTI, Agenor. Método Ver-Julgar-Agir. In: PASSOS, João Décio (Org.). Dicionário do Concílio Vaticano II. São Paulo: Paulus, 2015. pp. 608-615. 
humano, propondo um novo estilo de vida em benefício do bem comum e da compaixão pela Terra.

Para incentivar o leitor, apresentamos a seguir um pequeno "esboço", selecionando apenas algumas questões fundamentais dentro do imenso e rico conteúdo que cada um dos textos - Texto-Base da CFE2016 e a Encíclica Laudato Si - abordam.

\section{O contexto da nossa Casa Comum: um olhar sobre esta realidade}

Vive-se num mundo em constantes mudanças, onde todas as coisas parecem permanecer no estado de "fluidez", segundo o pensamento de Zygmunt Bauman, em sua obra Modernidade líquida. ${ }^{5}$ Diante desse aspecto, com relação ao projeto original do Criador narrado no Livro do Gênesis (cf. Gn 1,26-31), há uma ruptura não só exterior, mas também dentro de cada ser humano. "A harmonia entre o Criador, a humanidade e toda a criação foi destruída por termos pretendido ocupar o lugar de Deus, recusando reconhecer-nos como criaturas limitadas" ${ }^{6}$ Por isso, inúmeros desequilíbrios ambientais têm sido provocados pelo ser humano. Para curar esses descompassos exteriores, é fundamental curar o coração dos seres que os provocam e despertar em cada um e cada uma, o cuidado e a compaixão pela vida. ${ }^{7}$

Para a preservação da vida no planeta, urgem tomadas de atitudes e superação das desigualdades e das agressões à criação. De acordo com este estudo, tais escolhas só serão eficazes quando confrontadas com as realidades no âmbito do saneamento básico, que passam a incorporar não só questões de ordem sanitária, mas também jurídicas, principalmente para os pequenos e pobres ${ }^{8}$. O grande desafio, diz Leonardo Boff, é como inaugurar um novo paradigma do cuidado com a totalidade da vida, para humanizar, urbanizar e dar um rosto humano a esses milhões de pessoas

\footnotetext{
BAUMAN, Zygmunt. Modernidade líquida. Trad. Plínio Dentzien. Rio de Janeiro: Zahar, 2001. p.7.

6 LS, 66.

7 BOFF, Leonardo. Saber cuidar: ética do humano - compaixão pela terra. Petrópolis: Vozes, 2003. p. 102.

8 PONTIFÍCIO CONSELHO JUSTIÇA E PAZ. Compêndio da Doutrina Social da Igreja. Trad. CNBB, São Paulo: Paulinas, 2011, n. 412.
} 
que vivem no abandono, à margem da sociedade, sem infraestrutura, sem transporte, sem educação, sem segurança e sem comida. ${ }^{9}$

Nesse sentido, as reflexões levantadas ou as problemáticas trazidas no Texto - Base da CFE-2016 e na Laudato Si' são densas, refletidas e dialogadas não só entre as Igrejas Cristãs, mas com as outras áreas de conhecimento, como a Estatística, a Biologia, a Saúde Pública, a Filosofia, a Sociologia, a Teologia e a Política etc.10 Estudos elaborados com critérios científicos mostram os atrasos e os avanços na questão do saneamento básico no Brasil e a responsabilidade de todos no cuidado com a Casa Comum. ${ }^{11}$

Constata-se, tanto na primeira parte (ver) do Texto-Base, quanto no capítulo I da Encíclica, uma extensa elaboração de dados referentes ao saneamento básico, o que leva ao contundente questionamento do Papa Francisco: "O que está acontecendo com a nossa casa"? ${ }^{12}$ Devido ao grande volume de informações constantes nos dois documentos aqui referenciados, serão citados apenas seus subtítulos, que nada deixam a desejar, pois, por si só se explicam, inspiram e, certamente, poderão provocar nas pessoas com suficiente sensibilidade o desejo de buscar conhecer mais a grandiosidade de cada assunto neles tratado.

Primeiramente, no Texto-Base são citadas as grandes questões sobre saneamento básico e saúde; urgência do saneamento básico no Brasil; saneamento básico e o direito à moradia saudável; saneamento básico, cidades e resíduos e saneamento básico para além da cidade. Ainda, saneamento básico e água potável, uma relação vital; saneamento básico e produção industrial; saneamento básico e produção de lixo doméstico; saneamento básico e esgoto sanitário; saneamento básico e regionalização, e, por último, saneamento básico na legislação brasileira. ${ }^{13}$

Em segundo lugar, a Encíclica apresenta conteúdos que seguem a mesma linha de reflexão do Texto-Base sobre o "cuidado da Casa Comum" com os seguintes temas: poluição e mudanças climáticas; o clima como bem comum; a questão da água; perda da biodiversidade;

9 BOFF, Leonardo. Saber cuidar: ética do humano, compaixão pela terra. Petrópolis: Vozes, 2003. pp. 17-18.

10 LS, 201.

11 TEXTO-BASE, 97 a 112.

12 LS, 17-18.

13 TEXTO-BASE, 29 a 114, p. 15-37. 
deterioração da qualidade de vida humana e degradação social; desigualdade planetária; a fraqueza das reações e diversidade de opiniões. O Papa faz uma descrição da atual crise ambiental, assumindo para isto os resultados das pesquisas científicas publicadas, para deixar-se tocar por ela em profundidade e dar uma base concreta ao percurso ético e espiritual a ser seguido. ${ }^{14}$ Esse conteúdo da Laudato Si'é decisivo para o entendimento da crise pela qual passamos. Assim, seguiremos pontuando alguns tópicos considerados imprescindíveis para nossa reflexão.

\section{Educação e meio ambiente: quem cuida?}

Segundo observação do professor José Pacheco ${ }^{15}$, é provável que muitas crianças e jovens passem cerca de uma década ou mais, estudando a necessidade de cuidar dos recursos naturais em manuais e livros didáticos, numa escola que se mantenha à margem de uma possibilidade concreta de intervenção no contexto real de seu cotidiano. É provável também que uma criança ingresse na primeira série em uma escola ao lado de um córrego poluído e saia de lá, ao cabo de alguns anos, com o córrego mais poluído ainda. É bem provável que os seus professores, resguardados entre as quatro paredes de suas respectivas salas de aula, atravessem décadas sem lançar um olhar sequer para além dos muros da escola. ${ }^{16}$

Quantas mais situações degradantes podemos observar, para constatar que a terra está doente porque nós estamos doentes? Certamente todos continuarão doentes enquanto a nossa maneira de viver for reproduzida nos valores que muitas escolas insistem em transmitir, ou seja, onde a educação de um novo sentido de vida não se dá. ${ }^{17}$ Devemos temer toda a racionalidade que prevalece na maioria das práticas escolares hoje, na medida em que transmitem às crianças um conjunto cada vez maior de informações e conhecimentos, em contexto capitalista, onde elas são educadas para ingressar no mundo do trabalho e consequentemente

\footnotetext{
14 Cf. LS, 20 a 61.

15 Educador português, mestre em Ciências da Educação pela Faculdade de Psicologia e Ciências da Educação da Universidade do Porto. Fundador da Escola da Ponte em 1976. Hoje, reside no Brasil. PACHECO, José. Dicionário de Valores. São Paulo: SM, 2012. p. 32.

17 SUNG, Jung Mo. Educar para reencantar a vida: Pedagogia e espiritualidade. São Paulo: Reflexão, 2012. pp. 104-105.
} 
para a cultura do consumo. ${ }^{18}$ Tais práticas poderão augurar tempos ainda mais sombrios e desencadear graves conflitos socioambientais. Por isso, é preciso enfrentar esse desafio, diz Jung Mo Sung, e "reencontrar um sentido para a educação que não seja um mero meio para reproduzir a cultura de consumo e a lógica da acumulação que dominam a nossa sociedade". ${ }^{19}$ Podemos pensar também que uma escolarização prolongada e integral - família, escola e sociedade - poderá proporcionar uma maior consciência ambiental, considerando que nenhuma escola deve permanecer distante da vida real. ${ }^{20}$

Urge instituir novas práticas sociais nos lugares onde a educação do caráter e da ética acontece ${ }^{21}$. Conscientes dessa necessidade, a título de ilustrar o pensamento, citamos o belíssimo trecho de uma das cartas que Walter Steurer ${ }^{22}$ escreveu ao amigo José Pacheco:

Por muito tempo tratamos a Terra como algo a nosso serviço, que podíamos aproveitar ilimitadamente. Nunca pensamos na Terra como sendo nós também parte dela, de seu complexo sistema de vida. O Projeto Ancora tem intensificado cada vez mais o trabalho de consciência ecológica com as crianças e jovens. Acreditamos que esses meninos e meninas além de estarem abertos, mais que os adultos, às necessidades de mudanças em comportamentos e atitudes, sabem que são capazes de influenciar suas famílias. Nossos índios detêm a sabedoria capaz de nos salvar com o Planeta, são capazes de viver em liberdade, tirando da Terra somente o necessário, com uma organização social que não conhece a corrupção, onde o enriquecimento não faz parte das aspirações pessoais, onde o bem estar coletivo está acima de tudo. Em nosso dia a dia, podemos usar a Carta da Terra como nosso código de conduta. Alegremo-nos por viver neste momento da história humana, onde nos é dada a possibilidade de mudar o rumo da história e salvarmo-nos da destruição da vida. ${ }^{23}$

18 Ibidem, p. 105.

19 Ibidem, p. 107.

20 PACHECO, José. Dicionário de Valores: Meio Ambiente. São Paulo: SM, 2012. p. 32.

21 Cf. MORIN, Edgard. Os sete saberes para uma educação do futuro. Trad. Catarina Eleonora F. da Silva e Jeanne Sawaya. São Paulo: Cortez, 2002. p. 106.

22 Walter Steurer (1940-2011) foi o fundador do "Projeto Âncora", um espaço para aprendizagem, prática e cidadania, criado em setembro de 1995, na cidade de Cotia, SP. Hoje, ampliado para obras sociais para atender comunidades carentes.

23 PACHECO, José. Dicionário de Valores: Meio Ambiente. São Paulo: SM, 2012. p. 33. 
É importante, é preciso que o tema da "Educação em Valores" esteja de forma clara na agenda das escolas e dos professores. Mais ainda, esteja cada vez mais presente nos projetos político-pedagógicos, em projetos transversais e em ações de formação continuada de toda a comunidade educacional. No contexto do mundo contemporâneo, com tantas incertezas, tantos desafios e problemas, formar cidadãos com princípios éticos e valores humanistas sólidos é verdadeira condição de existência necessária para todos..$^{24}$ Acreditamos que o caminho mais curto onde cada pessoa poderá enriquecer sua personalidade e facilitar seu acesso ao verdadeiro, ao justo e ao belo será através da educação humanizadora, que por si só justifica e ilumina todos os outros caminhos.

Do mesmo modo, é igualmente importante para os cristãos de hoje voltar às narrativas sagradas, reconhecendo nelas todo o amor do Criador para com as suas criaturas, chamando-as a viver com liberdade e responsabilidade, cuidando para que todos e todas tenham vida em abundância (cf. Jo 10,10), conforme reflexões a seguir.

\section{Laudato Si: a inspiração que emerge do texto bíblico}

Hoje, o mundo encontra-se marcado pelas divisões, conflitos, crises ambientais, econômicas, políticas, culturais e religiosas. O ser humano está perdendo o equilíbrio de sua integridade na relação com o outro, esquecendo-se que desde a origem do mundo tudo está conectado, como nos ensinam as grandes tradições religiosas e as civilizações autóctones. $\mathrm{O}$ ato de ler o mundo, de desvelar a realidade é atentar para os sinais dos tempos hoje. ${ }^{25}$ Mas, há algo muito importante a ser considerado. Como discernir tais sinais? Para os que professam a fé cristã, em particular, são chamados a "recuperar a identidade de discípulos e seguidores de Jesus" ${ }^{26}$. Por isso, tanto o Texto-Base quanto a Laudato Si trazem, cada um, um capítulo inteiro referente às convicções da fé. Não se pretende aqui fazer um estudo exegético dos textos bíblicos. Todavia, por eles conterem a revelação do rosto misericordioso de Deus Criador, através

24 MORIN, Edgard. Os sete saberes para uma educação do futuro. Trad. Catarina Eleonora F. da Silva e Jeanne Sawaya. São Paulo: Cortez, 2002. pp. 84-85, 106.

25 Cf. BOFF, Clodovis M. Sinais dos Tempos: princípios de leitura. São Paulo: Loyola, 1979.

26 Cf. PAGOLA, José Antonio. Voltar a Jesus: para a renovação das paróquias e comunidades. Trad. Gentil Avelino Titton, Petrópolis: Vozes. 2015. p. 51. 
da pessoa de Jesus Cristo, considera-se necessário apresentar apenas aqueles textos tomados como referência nos respectivos documentos.

A Bíblia narra uma revelação progressiva. Antes mesmo que Jesus Cristo fizesse a plena revelação de Deus Pai, os profetas já anunciavam aspectos importantes da caridade e da justiça, fundamentos do Reino de Deus entre os homens. O bem comum, desejado por Deus é o grande objetivo das Sagradas Escrituras. Da humanidade, ao aderir ao projeto do Reino de Deus e o compromisso com a construção do bem comum, dependerá a salvação de todas as criaturas. Falar do bem comum, não é restringi-lo somente à relação dos seres humanos entre si, mas também destes com a natureza, que deve ser cuidada com gratidão e respeito. $\mathrm{O}$ uso da natureza e de todos os bens materiais deve acontecer de forma justa, voltada para a construção de uma coletividade amorosa e com mais igualdade, ao invés de serem utilizados para suprir a individualidade, o egoísmo e a ganância de alguns. ${ }^{27}$

A escolha do texto de Amós, "Quero ver o direito brotar como fonte e correr a justiça qual riacho que não seca" (Am 5,24), não foi por acaso. O profeta fundamenta sua pregação numa denúncia social aguda, chamando a atenção para um progresso econômico que não se traduzia em igualdade e justiça para todos. Aponta para uma situação de caos social, onde as relações afetivas estavam se rompendo (Am 2,6-8). Amós revela que a fé em Deus estava sendo manipulada pela religião oficial (Am 4,4-5). A vontade de Deus é que todos sejam alcançados pela justiça e possam viver com dignidade. Não somente Israel e Judá (Am 9,7-8) ${ }^{28}$

No segundo capítulo da sua Encíclica, o Papa Francisco faz um convite para que possamos conhecer e aprofundar o "Evangelho da Criação" a partir da retomada de algumas argumentações que derivam da tradição judaico-cristã, a fim de dar maior coerência ao compromisso e a responsabilidade que cada ser humano tem com o meio ambiente. Faz menção à sabedoria das narrativas bíblicas e ao que dizem essas grandes narrativas sobre a relação do ser humano com o mundo, sem propor toda a teologia da Criação. Cita diversos versículos do capítulo um do livro do Gênesis (cf. Gn 1,26-36), onde "a Bíblia ensina que cada ser humano é criado por amor, feito à imagem e semelhança de Deus". ${ }^{29}$ Esta afirmação

\footnotetext{
27 TEXTO-BASE, n. 116, p. 39.

28 Ibidem, n. 118-162, p. 40-52.

29 LS, 65.
} 
mostra a imensa dignidade de cada pessoa humana, que não se qualifica como alguma coisa, mas alguém que é capaz de se conhecer e de se dar em comunhão com as outras pessoas. ${ }^{30}$

Desde o princípio, conforme a abordagem no livro do Gênesis (Gn 1-11), sobre as narrativas da criação, o Criador nos deu a conhecer que toda pessoa é sua imagem e semelhança. Em sua infinita bondade, Deus criou o céu e a terra, e os iluminou com uma luz intensa, separando a luz da escuridão, como o dia e a noite. Deus criou as águas debaixo do céu, e na terra seca fez brotar toda a vegetação, ervas que dão sementes e árvores que dão flores e frutos. Criou os luzeiros no firmamento do céu para iluminar a terra: o sol e a lua, e também as estrelas. Encheu as águas de seres vivos, povoou o céu com as mais diversas aves e borboletas, e a terra com muitas espécies de animais. Por fim, Deus criou o ser humano à sua imagem, abençoou-os e disse: "Sejam fecundos, multipliquem-se, encham a terra e a submetam" (Gn 1,1-28).

Diante dessa narrativa percebemos que a gratuidade de Deus criador é absoluta e plena. $\mathrm{O}$ fato de que o homem é imagem e semelhança de Deus significa que em consequência disso a mais profunda característica do ser humano é a de ser criatura agraciada por excelência, porque a vida é o dom primeiro e fontal. ${ }^{31}$ A ternura e misericórdia de Deus preferiram, desde o princípio, remeter o ser humano ao próprio Criador, ou seja, o ser humano não tem o ponto de referência em si mesmo, mas em Deus, ${ }^{32}$ e por isso lhe é próprio afirmar, citando Santo Agostinho: "Senhor, criando-nos Tu nos colocaste no caminho que conduz a Ti e o nosso coração está inquieto enquanto não repousa em Ti". ${ }^{33}$

A criação é dom recebido e, portanto, é certamente tarefa a ser cumprida. "A maneira de receber o dom e exercer a missão requer da pessoa humana fidelidade a si mesma e a Deus, para cuidar da criação". ${ }^{34}$ Todo o ser humano deve ser capaz de desenvolver suas potencialidades e, em comunhão com o Senhor efetuar sua própria realização em atitude

\footnotetext{
30 DAp, 155.

$31 \mathrm{EV}, 2$

32 Cf. ROCCHETTA, Carlo. Teologia da ternura: um "evangelho" a descobrir. São Paulo: Paulus, 2002. p. 499.

33 AGOStINHO, Santo. Confissões. Trad. Maria Luíza Jardim Amarentes. São Paulo: Paulus, 1997. p. 10.

34 WEIZENMANN, Mariano. Leitura ecológica e algumas releituras teo(eco)lógicas de Gn 1-11. In. TQ Teologia em Questão. Taubaté, 2004, Ano III, n. 5, p. 36.
} 
de amor e fidelidade à sua vida e a vida de todas as criaturas. Por isso mesmo o fiel ora:

Deus dos pais e Senhor de misericórdia, que tudo criaste com tua palavra, e com tua sabedoria preparaste o ser humano para dominar sobre as criaturas que fizeste existir; e para governar o mundo com santidade e justiça, e para realizar o julgamento com retidão de alma; concede-me a sabedoria que se assenta contigo no trono, e não me excluas do número de teus filhos ( $\mathrm{Sb} 9,1-4)$.

Cuidar da criação significa preservá-la na sua forma original, mantendo-a bela, porque foi assim: "E Deus viu que tudo o que havia feito, e tudo era muito bom" (Gn 1,1-31). Esse texto do Livro do Gênesis nos convida a refletir sobre a nossa relação com a natureza e como nós, seres humanos, devemos ter gestos amorosos, compassivos, agindo com responsabilidade e fraternidade para com todas as criaturas. Vamos pinçar alguns exemplos.

\section{Responsabilidade e fraternidade: ações através do diálogo}

A contemplação da realidade atual da humanidade, tanto nas feridas do planeta em que habitamos como nas causas mais profundamente humanas da degradação do meio ambiente, indica a necessidade de uma mudança de rumo e sugere algumas ações que ajudem a humanidade a sair da espiral de autodestruição em que se encontra. ${ }^{35} \mathrm{O}$ diálogo e o trabalho conjunto em favor do bem comum são testemunhos importantes a oferecer para a sociedade ${ }^{36}$. A Campanha da Fraternidade Ecumênica deve motivar o encontro de todas as pessoas - católicas, evangélicas, espíritas, outras religiões e até mesmo os ateus - para que se possam construir ações conjuntas que favoreçam o cuidado com a nossa Casa Comum.

O tema: "Casa Comum, nossa responsabilidade" é uma orientação para que toda a sociedade possa atuar coletivamente em favor da elaboração, implementação e acompanhamento dos Planos Municipais de Saneamento Básico. As responsabilidades são coletivas, porém diferenciadas, ou seja, o poder público tem a tarefa de realizar as obras

35 COMBLIN, José. Quais os desafios dos temas teológicos atuais? São Paulo: Paulus, pp. 82-83.

36 Cf. LS, cap. V. 
de infraestrutura, programar o Plano Municipal de Saneamento Básico, garantir a limpeza do espaço público e fazer a coleta seletiva do lixo. Por outro lado, os cidadãos têm a tarefa de não jogar lixo nas ruas e zelar pelos espaços coletivos, entre outras. Estas atitudes poderão nos aproximar do sonho do profeta Amós que é o de "ver o direito brotar como fonte e correr a justiça qual riacho que não seca" (Am 5,24). ${ }^{37}$

Ao propor um diálogo sobre o meio ambiente e as políticas internacionais e nacionais, a fim de que se possa entender a necessidade da transparência nos processos decisórios, a Encíclica explicita, no quinto capítulo, "algumas linhas de orientação e ação". ${ }^{38}$ O Papa diz que o estudo de impacto ambiental para viabilizar os empreendimentos deve ser elaborado de forma interdisciplinar, transparente e interdependente e, por isso, todos devem participar dessas decisões e perguntar sempre: "Para que fim? Por qual motivo? Onde? Quando? De que maneira? A quem ajuda? Quais são os riscos? A que preço? Quem paga as despesas e como o fará"? Ao final do capítulo, articula as bases que são necessárias para o diálogo entre religiões e ciências. ${ }^{39}$

O Papa Francisco diz ainda que ele está finalmente convencido de que toda mudança tem necessidade de motivações e de um caminho educativo e, nesse sentido, propõe no sexto capítulo temas para o entendimento de uma "educação e espiritualidade ecológicas". ${ }^{40}$ Expõe com beleza e profundidade a necessidade de se ter outro estilo de vida, que devemos educar para aliança entre humanidade e meio ambiente, para a conversão ecológica, buscando alegria e paz. Essas linhas de ações para a Educação Ambiental estão inspiradas no tesouro da experiência espiritual cristã. ${ }^{41}$

\section{Considerações finais}

Cabe aqui fazer ainda algumas ponderações acerca do que já foi evidenciado ao longo do trabalho, a fim de destacar a grande semelhança no teor dos dois textos, sabendo-se que, embora, tenham sido escritos quase que simultaneamente, foram produções independentes. Considerando que o Espírito sopra onde e quando quer, a coincidência parece ser Providência Divina.

\footnotetext{
37 TEXTO-BASE, n. 163-196.

38

LS, 163.

39 LS, n. 164-201.

40 Cf. LS, cap. VI.

41 LS, n. 202-246.
} 
Refletindo sobre tudo isso, fica claro que a bondade e fidelidade de Deus se manifestam constantemente entre todas as criaturas dessa "Casa Comum".

O tema central "Casa Comum: nossa responsabilidade" quer motivar a constante leitura do Texto-Base e da Encíclica, e de tudo que se relaciona a esse assunto. Neste vasto universo de informações, há um aspecto necessário a ser destacado, que são as iniciativas individuais necessárias para que as mudanças aconteçam. É preciso que em nosso dia a dia estejamos abertos às necessidades de mudanças em comportamentos e atitudes para a capacidade de influenciar as outras pessoas. Que possamos deter a sabedoria capaz de nos salvar com o Planeta, vivendo a liberdade com uma organização social que não conheça a corrupção e tirando da Terra somente o necessário, para que o bem-estar coletivo esteja acima de tudo.

Quanto ao saneamento básico, urge instituir novas práticas sociais e educacionais em toda a sociedade. Ele envolve o poder público, mas também cada cidadão e cidadã. A participação e o acesso às discussões devem ser públicos para que a sociedade veja o que está sendo feito e, ao mesmo tempo, que essa mesma sociedade tenha um lugar de referência a fim de oferecer sugestões concretas para a melhoria dos serviços. Lembrando que a Campanha da Fraternidade de cada ano não termina e nem pode terminar com a Quaresma, pois é a partir desse tempo precisamente, o tempo propício para a vivência de uma abundante práxis cristã.

O Papa Francisco inicia a Carta Encíclica convidando toda a família humana a buscar um desenvolvimento sustentável e integral e a colaborar na construção da nossa "Casa Comum". Lança um convite urgente a renovar o diálogo sobre a maneira como estamos construindo o futuro do planeta, considerando todo o esforço feito por muitos movimentos ecológicos que já percorreram um rico caminho. Mas reflete que ainda há indiferença, acomodação e falta de solidariedade universal no esforço para com o cuidado da criação. Por isso, espera que esta Carta ajude a reconhecer a grandeza, a urgência e a beleza do desafio que temos pela frente.

Por fim, consideramos ainda que estes documentos contêm uma riqueza de ensinamentos em seus termos quase que inesgotáveis, que nos falam da necessidade de uma metamorfose, de uma reforma moral, lograda através de profundas mudanças no modo de educar e numa economia ecológica e solidária. Eis alguns exemplos: "Autonomia, cidadania, responsabilidade, solidariedade, justiça, cuidado com a Casa Comum". É necessário contemplarmos a beleza desses textos como valor a ser desenvolvido na prática. 
Muitas vezes nos esquecemos de que a beleza está nos olhos de quem vê, de quem sente, e, ela requer um exercício de sensibilidade. $\mathrm{O}$ fato é surpreendente, porque toda a Criação Divina é um ato estético ou não é Criação Divina. Sem a vivência da beleza, somos impedidos de experimentar o amor e a liberdade, que juntos nos conduzem pelos caminhos da sabedoria e da esperança de que "um mundo melhor é possível".

Não foi nossa intenção reescrever na íntegra os conteúdos do Texto-Base da Campanha Ecumênica da Fraternidade de 2016 e da Encíclica Laudato Si' do Papa Francisco, e, tampouco escrever algo novo. Mas, nas entrelinhas deste artigo, esperamos que o leitor encontre contributos para repensar sobre a vida do Planeta Terra que é a nossa "Casa Comum" e conceber uma nova construção social amorosa, que, efetivamente, eduque e seja agente de desenvolvimento humano sustentável.

Que possamos ter esperança com significado de fé na bondade da natureza humana, para confiar e acreditar que é possível ensinar e aprender o diálogo, o reconhecimento da diversidade, a amorosidade, a solidariedade, a alegria, a justiça, a ética, a responsabilidade social, o respeito, a cidadania e a humanização de todos os povos.

\section{Referências Bibliográficas}

AGOSTINHO, Santo. Confissões. Tradução Maria Luíza Jardim Amarantes (Patrística 10). São Paulo: Paulus, 1997.

BAUMAN, Zygmunt. Modernidade Líquida. Tradução Plínio Dentzien, Rio de Janeiro: Zahar, 2001.

BÍBLIA DE JERUSALÉM. São Paulo: Paulus, 2008.

BOFF, Clodovis M. Sinais dos tempos: princípios de leitura. São Paulo: Loyola, 1979.

BOFF, Leonardo. Saber cuidar: ética do humano - compaixão pela terra. $9^{a}$ ed. Petrópolis: Vozes, 2003.

BOFF, Leonardo. Entrevista: Cuidar da Casa Comum, compromisso com o futuro. Assunto: Ensino Religioso. In: Jornal Mundo Jovem - ISS n. 1677-1451, ano 54, n. 463, fev. 2016.

BRIGHENTI, Agenor. A Igreja perplexa: a novas perguntas, novas respostas. São Paulo: Paulinas, 2004. 
BRIGHENTI, Agenor. Método Ver-Julgar-Agir. In: PASSOS, João Décio (Org.). Dicionário do Concílio Vaticano II. São Paulo: Paulus, 2015.

CELAM. Conselho Episcopal Latino-Americano. Documento de Aparecida: Texto conclusivo da V Conferência Geral do Episcopado Latino-Americano e do Caribe. São Paulo: Paulus, 2008.

CNBB. Diretório Nacional de Catequese (DNC) - Doc. n. 84. Brasília: CNBB, 2006.

COMBLIN, José. Quais os desafios dos temas teológicos atuais? São Paulo: Paulus, 2005. (Coleção Questões fundamentais da fé, 6. Coordenação Darci Luiz Marin).

CONIC. Conselho Nacional de Igrejas Cristãs do Brasil. Campanha da Fraternidade Ecumênica 2016: Texto-Base. Brasília: CNBB, 2015.

FRANCISCO Papa. Carta Encíclica Laudato Si' sobre o Cuidado da Casa Comum, São Paulo: Paulinas, 2015.

JOÃO PAULO II. Carta encíclica Evangelium Vitae sobre o valor e a inviolabilidade da vida humana. São Paulo: Paulinas, 2009.

MORIN, Edgard. Os sete saberes para uma educação do futuro. Trad. Catarina Eleonora F. da Silva e Jeanne Sawaya. São Paulo: Cortez, 2002.

PACHECO, José. Dicionário de valores. 1. ed. São Paulo: SM, 2012.

PAGOLA, José Antonio. Voltar a Jesus: para a renovação das paróquias e comunidades; tradução de Gentil Avelino Titton. Petrópolis: Vozes. 2015.

PONTIFÍCIO CONSELHO JUSTIÇA E PAZ. Compêndio da Doutrina Social da Igreja. Tradução Conferência Nacional dos Bispos do Brasil-CNBB. 7. ed. São Paulo: Paulinas, 2011.

ROCCHETTA, Carlo. Teologia da ternura: um "evangelho" a descobrir. São Paulo: Paulus, 2002.

SUNG, Jung Mo. Educar para reencantar a vida: Pedagogia e espiritualidade. São Paulo: Reflexão, 2012.

SUNG, Jung Mo. Deus numa economia sem coração. Pobreza e neoliberalismo: um desafio à evangelização. São Paulo: Paulus, 1992.

WEIZENMANN, Mariano. Artigo: Leitura ecológica e algumas releituras teo(eco)lógicas de Gn 1-11. In: Revista Teologia em Questão (TQ). Faculdade Dehoniana, Taubaté/SP, 2004 - Ano III - n. 5, p. 36. 